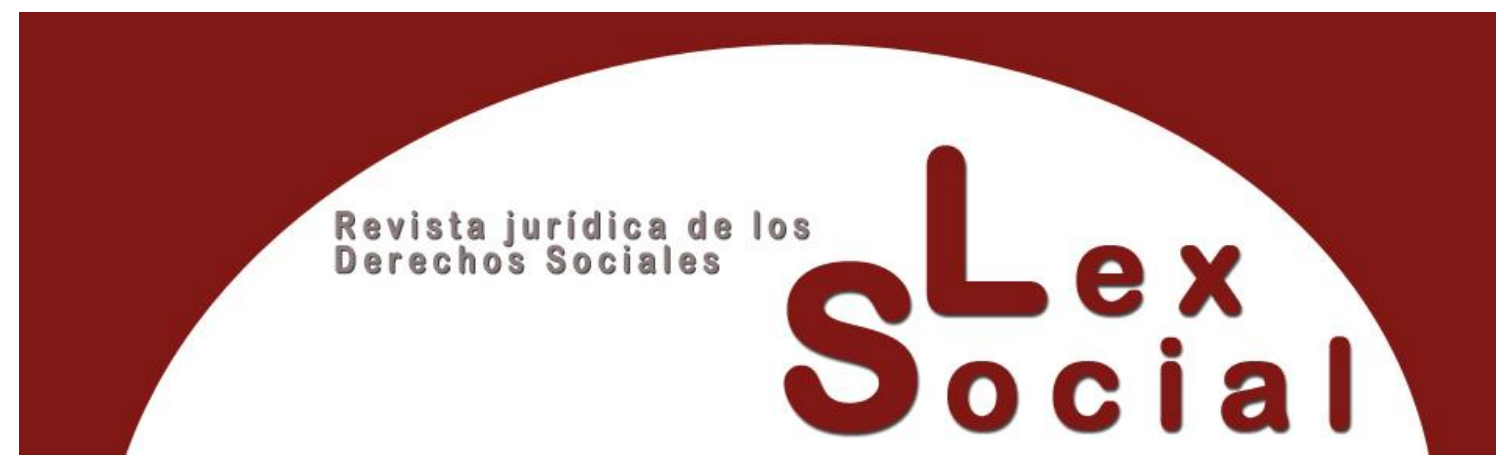

\title{
LA PRECARIZACIÓN COMO REALIDAD DE MERCADO: LA FRONTERA ENTRE EL EMPLEO DOMÉSTICO Y EL TRABAJO DE CUIDADOS
}

\author{
PRECARISATION AS A MARKET REALITY: THE BORDER \\ BETWEEN DOMESTIC EMPLOYMENT AND CARE WORK
}

CONCEPCIÓN SANZ SÁEZ

Profesora de Derecho del Trabajo y Seguridad Social

Universidad de Castilla-La Mancha

https://orcid.org/0000-0001-9783-9272

Cómo citar este trabajo: Sanz Sáez, C. (2021). La controvertida indemnización por lesión de los derechos fundamentales de las personas trabajadoras. Lex Social: Revista De Derechos Sociales, 11(1), 509-533. https://doi.org/10.46661/lexsocial.5497

\section{RESUMEN}

Debemos partir de la base en este estudio, de que las labores domésticas y de cuidado son trabajo. Se hace esta afirmación, porque como sabemos, desde las primeras manifestaciones de la prestación de este tipo de trabajo, se encuentra ligado al servilismo, y aunque desde hace años, se ha señalado la mala calidad de estos empleos, se sigue manteniendo un vínculo con la presente esclavitud, pero ahora, disfrazada con distintas normas legales.

\footnotetext{
${ }^{1}$ Este trabajo se encuadra en las actividades del Laboratorio de Derecho Social, línea de estudio Trabajo Doméstico y del Seminario Permanente de Trabajo Doméstico de la UC3M, Proyecto subvencionado en la convocatoria 2019, IMIO, 12/4ACT, ambos dirigidos por la profesora Ma . Gema Quintero Lima. Es éste el resultado definitivo, actualizado y cerrado de una investigación que se tuvo la oportunidad de, primero, divulgar en la plataforma The Conversation (https://theconversation.com/empleo-domestico-igualdad-yformacion-profesional-139065) y, segundo, presentar y exponer en formato póster en el III Congreso Mundial CIELO LABORAL «Quel Rôle pour les entreprises, les travailleur, les organisations représentatives, les citoyens et les États dans le Droit du travail et de la protection sociale du 21ème siècle?», 24-25 septiembre de 2020 (https://cielo2020.sciencesconf.org/resource/page/id/31).
} 
En la actualidad, los modos tradicionales de atender las necesidades del de estas actividades están en crisis debido al desequilibrio entre la oferta y la demanda, como producto de un mayor número de personas que lo requieren (por el envejecimiento de la población y el aumento de la esperanza de vida de las personas, por ejemplo) y, al mismo tiempo, debido a la menor proporción de personas en condiciones de proveerlos, principalmente por la mayor incorporación de las mujeres al mercado de trabajo.

Palabras Clave: Trabajo doméstico, cuidados, mujeres, migrantes, corresponsabilidad.

\begin{abstract}
We must start from the base in this study, that housework and care are work. This statement is made, because as we know, from the first manifestations of the provision of this type of work, it is linked to servility, and although for years, the poor quality of these jobs has been pointed out, a link with the current slavery, but now, disguised with different legal norms.

At present, the traditional ways of attending to the needs of these activities are in crisis due to the imbalance between supply and demand, as a result of a greater number of people who require it (due to the aging of the population and the increase in the life expectancy of people, for example) and, at the same time, due to the lower proportion of people in a position to provide them, mainly due to the greater incorporation of women into the labor market.
\end{abstract}

KEYWORDS: Domestic work, care, women, migrants, co-responsibility.

SUMARIO

I. Introducción

II. La situación de desigualdad ante la corresponsabilidad por orden de género y división sexual del trabajo

1. Restricciones ante la división sexual en la participación de las labores domésticas $y$ de cuidados

2. La privatización, invisibilización y feminización del trabajo de cuidados

III. El cuidado como eje central del bienestar

IV. El empleo doméstico y de cuidados como perfiles convergentes de la profesionalización

1. El futuro del trabajo decente de cuidados

$V$. Reflexiones finales

Bibliografía 


\section{Introducción}

Como ya ha sido generosamente publicado por la literatura ${ }^{2}$, la incorporación de las mujeres españolas al mercado de trabajo, el progresivo envejecimiento de la población, junto con una falta en la cobertura institucional para el cuidado de personas dependientes, ha generado la creación de un filón de empleo específico, como es el de cuidado ${ }^{3}$.

La última Encuesta sobre Discapacidades, Autonomía Personal y Situaciones de Dependencia ${ }^{4}$, indica que existen 3,8 millones de personas con alguna discapacidad, lo que supone el $8,5 \%$ de la población. Remitiéndonos al colectivo de más de 65 años, las cifras indican que el 30,5\% de las personas mayores poseen algún tipo de discapacidad que está asociada a una dependencia en un 21,6\%. Es decir, las estadísticas confirman que hay muchas personas que necesitan de la ayuda de una tercera persona para realizar las actividades básicas de la vida diaria ${ }^{5}$. En consecuencia, y evaluando los datos más recientes del Instituto Nacional de Estadística, este envejecimiento se acentuará todavía más en el futuro, ya que del 18,7 \% de personas mayores de 65 años se pasará a un 25,6\% en el $2031^{6}$. Por lo tanto, la necesidad de personas cuidadoras aumentará como decimos.

\footnotetext{
${ }^{2}$ Entre otros, CARRASCO, Cristina., BORDERÍAS, Cristina y TORNS, Teresa. (EDS.), El trabajo de cuidados. Historia, teoría y políticas. Catarata, Madrid, 2011. GARCÍA SAINZ, C. "Entre la ciencia y vida cotidiana". El cuidado de las personas como objeto de conocimiento. En Sociología y realidad social Libro homenaje a Miguel Beltrán Villalva, G. Meil Landwerlin y C. Torres Albero, 2008. págs. 725- 741. España: CIS. TORNS, Teresa. "El trabajo de cuidados: un camino para repensar el bienestar". En Papeles de relaciones ecosociales y cambio global, T. Torns (ed.), 2012. págs. 93-101. FUHEM TORNS, Teresa. Políticas de tiempos políticas para el bienestar. ¿Tiempos para la igualdad? Reflexiones sobre el tiempo, el género y la organización social. España: Emkunde-Instituto Vasco de la Mujer. 2010.

${ }^{3}$ Como pone de manifiesto el informe Perspectivas sociales y del empleo en el mundo. Tendencias 2015 de la OIT. https://www.ilo.org/global/research/global-reports/weso/2015/lang--es/index.htm (consultada el $26 / 11 / 2020)$

${ }^{4}$ El Instituto Nacional de Estadística tiene previsto publicar en 2021 una nueva encuesta "Discapacidad, Autonomía Personas y situaciones de Dependencia", para actualizar los datos sobre personas con discapacidad en España, ya que el último estudio publicado es este de 2008 con cifras de 2007.

${ }^{5}$ Estas actividades están consideradas en todas las tablas que se presentan en este apartado son: lavarse, cuidados de las partes del cuerpo, higiene personal relacionada con la micción, higiene personal relacionada con la defecación, higiene personal relacionada con la menstruación, vestirse y desvestirse, comer y beber, cuidado de la propia salud: cumplir las prescripciones médicas, cuidado de la propia salud: evitar situaciones de peligro, adquisición de bienes y servicios, preparar comidas, realizar las tareas del hogar, cambiar las posturas corporales básicas, mantener la posición del cuerpo, desplazarse dentro del hogar, desplazarse fuera del hogar, uso intencionado de los sentidos (mirar, escuchar ...) y realizar tareas sencillas. ${ }^{6}$ Veasé el Cuadro A.2.3 en el Apéndice para las ratios nacionales de dependencia de cuidados de la tercera edad, página 358 del Informe completo. https://www.ilo.org/wcmsp5/groups/public/---dgreports/--dcomm/---publ/documents/publication/wcms_633135.pdf (consultado el 29/11/2020).
} 


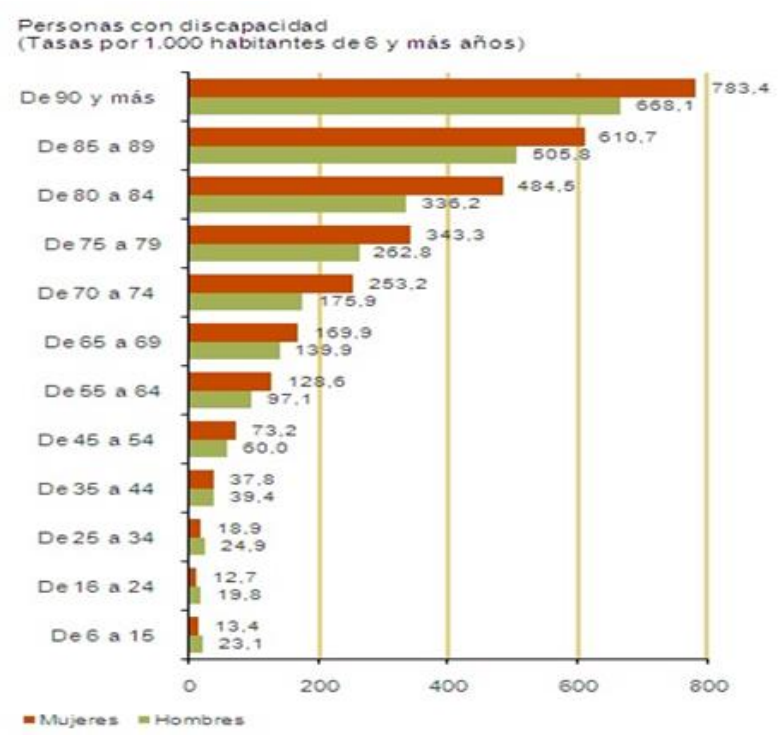

Fuente: Última Encuesta de Discapacidad Autonomía personal y situaciones de dependencia INE

Por esta razón, y en una economía de mercado como la que impera, donde se supone que la oferta y la demanda fijan los precios, este fenómeno de aumento de la demanda tendría que mejorar las condiciones de las trabajadoras del hogar y de cuidados, al entender que, si se cumple esta premisa, también su salario tendría que prosperar. Pero nada más lejos de la realidad, ya que siguiendo el trabajo de Parella Rubio", existe una "competencia desleal" por los bajos precios que pueden llegar a ofrecer las familias empleadoras y por la creciente internacionalización del trabajo que ha puesto un ejército de reserva formado por mujeres inmigrantes capaces de aceptar condiciones laborales que rozan el "servilismo".

Por esta razón, ya que las características laborales del servicio doméstico permiten una flexibilización de horarios, una adecuación entre el tiempo de atención y el desarrollo de las tareas domésticas y la presencia, mediante la modalidad de "interna", de una cuidadora permanente que esté pendiente de las necesidades del mayor durante las 24 horas diarias. La provisión de cuidados por empresas privadas tiene un coste económico tan elevado que pocos presupuestos familiares pueden soportar. Además, la frecuencia y el tiempo de cuidados que ofrecen no llegan para cubrir las necesidades de la población dependiente.

Si añadimos a todo lo anterior, el incumplimiento de la Administración en las tareas de asistencia personal provoca la extensión del sector doméstico y de cuidados privado. Este mercado de asistencia se ha modelado en nuestro país a partir del servicio doméstico y, en el actual contexto de migración internacional, se ha convertido en una oportunidad laboral para las mujeres inmigrantes.

Por tanto, en este estudio nos vamos a centrar en el análisis de los factores que, sustentan la elección de externalizar las tareas domésticas y de cuidado para evidenciar el peso de

${ }^{7}$ PARELLA RUBIO, Sonia. “Mujer, inmigrante y trabajadora: la triple discriminación”, Ciencias Sociales,

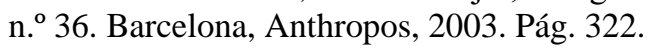


las desigualdades de género en el colectivo, a través del análisis de las principales razones desigualitarias específicas que constituyen obstáculos para el mejoramiento de estos empleos.

Con ese fin, se pretende contribuir a un mejor conocimiento de estos cambios en el trabajo del hogar que, por un lado, están relacionados con la transformación del servicio doméstico en un servicio de cuidados, intensificándose cada día más, pero que lo único que se está haciendo al respecto, es poner parches, y por otro, también se encuentran afectados por la actual coyuntura económica y por el marco legal establecido, no solamente para regular el empleo doméstico sino también el que propone delimitar las categorías de empleadas de hogar y de las cuidadoras no profesionales.

Sin duda, dignificar estos empleos es un asunto que debe ponerse sobre la mesa con urgencia. Los cuidados y empleo doméstico son trabajos invisibilizados, que sufren desprotección y precariedad, pero a la vez imprescindibles para el funcionamiento de la sociedad, como hemos podido comprobar durante la crisis sanitaria del Covid-19, que ha sido el momento en que la sociedad se da cuenta de la importancia del ejercicio de este trabajo dentro del hogar ${ }^{8}$, evidenciando que la labor que realizan no es cualquier cosa, por lo que se las debe reconocer los derechos como al resto de trabajadoras ${ }^{9}$.

\section{La situación de desigualdad ante la corresponsabilidad por orden de género y división sexual del trabajo}

Comenzaremos este apartado aclarando que puesto que la amplia mayoría de personas trabajadoras en el trabajo doméstico y de cuidados son mujeres, las diferentes observaciones se centrarán en la situación de fuerte precariedad que sufren especialmente las mujeres empleadas de hogar y de cuidados, y ello no se pretende realizar atendiendo a una forma de lenguaje sexista, sino en consonancia a la especialización por género y a la falta de una cultura de corresponsabilidad en materia de cuidados y tareas domésticas.

\begin{tabular}{l|l} 
Variables sociodemográficas & Cifras de cuidadores (2019) \\
\hline Género & \\
Hombres & 1.381 \\
Mujeres & 12.881 \\
\hline
\end{tabular}

Fuente: Instituto de Mayores y Servicios Sociales.

Para ponernos en situación, debemos tomar los conceptos de cuidado y servicio, ya no como relaciones que caracterizan exclusivamente las actividades de la producción doméstica, sino como medida de análisis de las actividades que llevamos a cabo los seres humanos en nuestras vidas, para poner en evidencia el impacto que las relaciones de género tienen en nuestras sociedades sexistas. De este modo, pasaríamos de hablar de las

\footnotetext{
${ }^{8}$ APARICIO RUIZ, María Germana, "Medidas especiales en tiempos de Covid-19: la situación laboral de los empleados de hogar”. Labos, Vol. 1, n. 3, págs. 69-84.

${ }^{9}$ SANZ SÁEZ, Concepción, "Sobre el subsidio extraordinario para las empleadas de hogar en la crisis del COVID-19”. Trabajo y derecho: nueva revista de actualidad y relaciones laborales, №. 67-68, 2020.
} 
actividades de cuidado y de servicio, a debatir de qué hay de cuidado y de servicio en cada actividad.

En consecuencia, en el sector doméstico de cuidados es común que la atención de personas se combine con las actividades de limpieza y mantenimiento del hogar, en consecuencia, al ser un trabajo realizado en el interior del domicilio, las cuidadoras, no son solamente eso, sino que se convierten en "chicas para todo", siendo esta situación especialmente preocupante en el régimen de interna.

Y para conceptualizar lo anterior, debemos retroceder al periodo en que se construyó el Estado del bienestar, en ese momento no se pensó que existiría la necesidad de cuidados que conocemos actualmente, por distintas razones, una de ellas la esperanza de vida, otra la mayor presencia de mujeres en el mercado de trabajo, pero también nos encontramos con la transformación de la familia nuclear patriarcal, como modelo social de género que mercantiliza de forma jerárquica a las personas, entre el ámbito público y reconocido (masculino) y el ámbito privado sin reconocimiento (femenino) ${ }^{10}$, con las implicaciones de desigualdad de oportunidades que esto supone, por no hablar del impacto de la constitución subjetiva que conlleva.

Por tanto, ante un panorama como el actual, donde cada vez existen más personas con necesidades de atención de cuidados pero, con la insuficiencia de servicios públicos adecuados a esta asistencia que tenemos, sumado al descenso de las mujeres llamadas coloquialmente "amas de casa" a tiempo completo, a las que se les asignaban las capacidades para el cuidado, por suponer que si eras mujer, ya lo sabias hacer; son cada vez más las familias que deciden contratar a mujeres con cierta experiencia informal en los cuidados, para que se hagan cargo de sus parientes ${ }^{11}$.

No obstante, y ya que me he referido a que en el caso de las mujeres, se entiende que aparentemente, el desarrollo ético de éstas se forma en un comportamiento natural dentro del cuidado, que se apoya en la noción fuerte de responsabilidad frente a las demás personas, me gustaría aclarar que la disposición para el cuidado, la responsabilidad y la solidaridad no serían parte de una naturaleza esencialmente femenina, sino que son consecuencia de las actitudes que las mujeres han generado a partir de su historia con las relaciones de cuidados ${ }^{12}$. Y tanto es así, que la realidad es que esta situación se ha convertido en una continua tensión entre las exigencias de las actividades profesionales y domésticas para las mujeres, que asumen los costos de la sobrecarga de trabajo, intensificándose en las situaciones de crisis y que cuestionan la aptitud de las políticas de

10 SÁEZ, Gemma, VALOR-SEGURA, Inmaculada y EXPÓSITO, Francisca. ¿Empoderamiento o subyugación de la mujer? Experiencias de cosificación sexual interpersonal. Psychosocial Intervention, 21, 2012. págs. 41-51.

${ }^{11}$ SARASA URDIALA, Sebastián. "La última red de servicios personales". En: J. Adelantado (Coord.). Cambios en el estado del bienestar: políticas sociales y desigualdades de España. Barcelona: Icaria-UAB. 2000, Págs. 347-378.

${ }^{12}$ CHACARTEGUI JÁVEGA, Consuelo. “Mujer, discriminación múltiple y exclusión social”. En: PÉREZ de la FUENTE ÓSCAR. Mujeres: luchando por la igualdad, reivindicando la diferencia. Madrid: Dykinson, 2010. págs. 39-62. 
conciliación, cuando no se producen cambios estructurales en la asignación del servicio y del cuidado ${ }^{13}$.

Y para afianzar esto, podemos recurrir como ejemplo de indicadores, al retraso, la reducción o la renuncia a la maternidad ${ }^{14}$; el establecimiento de nuevos marcos ideales, racionales y sentimentales del cuidado, y como no, la creciente práctica de externalizar estas labores ${ }^{15}$. A lo que debemos añadir que la carga de trabajo doméstico y de cuidados no remunerado depende de la estructura de los hogares: lo más común para la población femenina es que aumente cuando se pasa de vivir sola a vivir en pareja y se incremente con la llegada de hijas/os ${ }^{16}$. Sin embargo, cuando ellas logran obtener un tipo de posición dominante dentro de la jerarquía laboral, el "impuesto reproductivo" se manifiesta en un trabajo adicional no pagado ${ }^{17}$, aunque esta vez no necesariamente en forma de realización de las actividades domésticas y de cuidados sino de su gestión ${ }^{18}$, pero lo cierto es que en ambos casos el resultado final es menor ingreso y/o tiempo disponible para ellas.

\section{Restricciones ante la división sexual en la participación de las labores domésticas y de cuidados}

Para profundizar en esa situación de desigualdad por razón de género, considero que acudir al concepto de división sexual del trabajo es indispensable para analizar la forma en que el género funciona ante el trabajo doméstico y de cuidados. Aunque comúnmente con este concepto se designa la frontera que existe entre el espacio público y el ámbito doméstico. Y es que las actividades del espacio doméstico han sido consideradas más en términos de responsabilidad moral y biológica, con lo cual, no se han reconocido como un "trabajo formal" o remunerado. De esta forma, resulta que las actividades que realizan las mujeres no son las mismas que realizan los varones porque históricamente las actividades realizadas por varones son consideradas más importantes que las hechas por mujeres.

Por todo ello, quizás, es complicado hablar del fin de la familia nuclear patriarcal, habría que hablar de un "patriarcado diluido"19, en cuanto a que sus límites son más imprecisos,

\footnotetext{
${ }^{13}$ PÉREZ OROZCO, Amaia. “Amenaza tormenta: la crisis de los cuidados y la reorganización del sistema económico". Revista de Economía Crítica, 5, 2006. págs. 7-37.

${ }^{14}$ Encuesta de Fecundidad de 2018 del Instituto Nacional de Estadística. la encuesta refleja que el $42 \%$ de las mujeres residentes en España de edades comprendidas entre 18 y 55 años ha tenido su primer hijo más tarde de lo que consideraban ideal, un retraso que, de media, asciende a 5,2 años. Entre las razones se encuentran las circunstancias laborales, la conciliación de la vida familiar y laboral y las económicas.

15 INE. El 79,2\% de las mujeres de 25 a 29 años aún no ha tenido hijos. https://www.ine.es/prensa/ef_2018_d.pdf (consultada el 29/11/2020).

${ }_{16}$ CARRASCO BENGOA, Cristina. "La sostenibilidad de la vida humana: ¿Un asunto de mujeres?”, Mientras Tanto, núm. 82, 2001. págs. 43-70.

17 BARBERÁ HEREDIA, Esther. "Mas allá del techo de cristal". Revista del Ministerio de Trabajo y Asuntos Sociales, № 40. 2002, págs. 55-68

${ }^{18}$ En la $91^{\text {a }}$ Conferencia Internacional del Trabajo, celebrada en Ginebra, afirmaron que el porcentaje de hogares dirigidos por mujeres había aumentado en muchos países en desarrollo, fueran estos monoparentales o no.

19 DOMINIJANNI, Ida. "Después del patriarcado. Feminismo y cuestión masculina”. Ida Dominijanni, Fina Birulés, Àngela Lorena Fuster, Àngels Vivas (trads.). Lectora 23. 2016. Pág. 231.
} 
cambiantes y globales. Y me atrevo con esta manifestación, porque se puede afirmar que existe un aumento progresivo de mujeres en las actividades profesionales y esto no se ha convertido en el equivalente de hombres en las actividades domésticas y de cuidado, por lo que se debe admitir la falta de un cambio sustancial en la estructura de división sexual de este tipo de trabajos ${ }^{20}$.

Así pues, resulta indispensable revisar los medios y estrategias con los que las sociedades se organizan para responder a las necesidades del trabajo orientado al espacio doméstico y de cuidados, ya sea que este se asigne por medio del mercado (contratando cuidadoras o trabajadoras domésticas) o de otro tipo de mecanismo como el parentesco y las redes familiares o comunitarias.

La contratación de personal doméstico, como indicamos, es un recurso utilizado por las familias en situación socioeconómica favorable para la atención de las responsabilidades del hogar. De esta manera, genera una cantidad importante de empleo y se constituye en un recurso clave para la conciliación de las mujeres. Sin embargo, las trabajadoras domésticas no reciben un trato equitativo en relación con otras personas asalariadas. La normativa laboral y social que las ampara es restrictiva respecto a sus derechos y su aplicación aún no está generalizada, debido a la naturaleza de este trabajo que se realiza puertas adentro de la unidad familiar, entre otros motivos. En consecuencia, una proporción importante de las trabajadoras domésticas está empleada de manera informal, con salarios muy bajos, y con escasos derechos legales o protecciones sociales ${ }^{21}$. Todo ello resulta en oportunidades laborales en condiciones de precariedad que son tomadas por quienes no tienen posibilidades de elegir, con menores recurso o personas migrantes.

De esta manera, la división sexual del trabajo es importante porque esta diferenciación entre las actividades de hombres y las de mujeres organiza el poder y el prestigio en nuestras sociedades. Un elemento de esta separación descansa en las labores que unos y otras realizan podrían ser intercambiables, pero no es sencillo que lo sean porque están protegidas por las identidades sociales que se les asignan y con ello la distribución de trabajos, organizándose en términos jerárquicos, en perjuicio de las mujeres ${ }^{22}$.

\footnotetext{
${ }^{20}$ HARTMANN, Heidi. "Capitalismo, patriarcado y segregación de los empleos por sexos" en Cristina Borderías, Cristina Carrasco, Carmen Alemany (comps.), Las mujeres y el trabajo. Rupturas conceptuales, Fuhem/Icaria, Madrid/Barcelona, 1994, págs. 255 y 269.

${ }^{21}$ BUDIG, Michelle y MISRA, Joy. Los salarios de la economía del cuidado en comparación internacional. Revista Internacional del Trabajo, Vol. 119, Núm. 4. 2010, págs. 489-510.

${ }^{22}$ Los datos del Barómetro del CIS_indican que en un día laborable los hombres suelen dedicar 2,06 horas y las mujeres 3,84 horas al trabajo doméstico. Según esta encuesta, las mujeres se involucran prácticamente el doble de tiempo que los hombres. http://www.cis.es/cis/export/sites/default/Archivos/Marginales/3160 3179/3175/cru3175sexo.html (consultada el 19/11/2020).
} 
Una de las consecuencias de esto sobre la vida de las mujeres es, que sus cargas de trabajo doméstico y de cuidados son muy elevadas, reduciéndose sus posibilidades de realizar otro tipo de tareas destinadas a la recreación, el descanso, entre otras. Pues el modelo tradicional de familia (de hombre proveedor y mujer ama de casa) que prevaleció a lo largo de la historia conlleva una clara división de tareas entre generaciones y entre géneros. Pese a que en la actualidad las mujeres comparten con los hombres el tiempo de trabajo remunerado, no se ha generado un proceso de cambio similar en la redistribución de las tareas domésticas. Ellas siempre son responsables de esas labores, sean amas de casa o trabajen de manera remunerada. En consecuencia, su actividad se prolonga en una doble jornada laboral que involucra una sobrecarga de trabajo y limita su acceso al ocio y a oportunidades de capacitación y participación social.

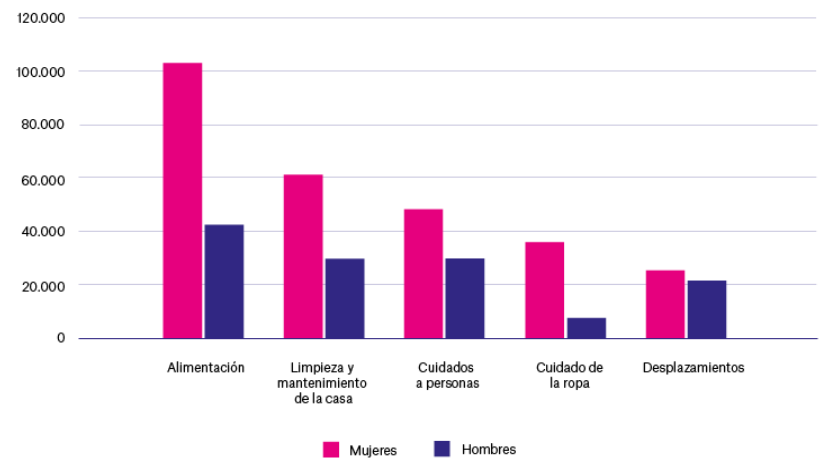

Aportación hombres y mujeres al trabajo no remunerado ${ }^{23}$

Debido a todo lo que antecede, aunque la reorganización de tareas socialmente necesarias con criterios de género más equitativos es una de las primeras formas de disminuir la sobrecarga de trabajo de las mujeres, es incuestionable que, en la búsqueda de distribuciones de tiempo socialmente equitativas, hay otras figuras que también podrían participar asumiendo parte de la responsabilidad del trabajo doméstico y de cuidados, para no dejar que se lleve a cabo exclusivamente dentro de los hogares ${ }^{24}$.

Esto trae aparejado un alto nivel de tensión para las trabajadoras con responsabilidades familiares, quienes continúan asumiendo la doble responsabilidad de trabajar dentro y fuera del hogar en forma predominante. Así, su creciente participación en el ámbito productivo, la valoración de su autonomía por ingresos propios, y su mayor ingreso y permanencia en la educación formal obligan a reflexionar sobre la rígida separación entre lo público y lo privado y, en alguna medida, la clásica división sexual del trabajo.

\footnotetext{
${ }^{23}$ ANGULO, Carlos y HERNÁNDEZ, Sara, "Propuesta de cuenta de producción de los hogares en España en 2010. Estimación de la serie 2003-2010", Documentos de Trabajo, 2015. Madrid: INE.

${ }^{24}$ Uno de los factores que inciden en la irregularidad de la situación laboral del servicio doméstico se vincula con el peculiar carácter del ámbito en el que se desarrolla la actividad laboral de estas trabajadoras (el hogar familiar), ámbito de difícil acceso al control directo por parte de la Inspección de Trabajo.
} 
Y en virtud de ello, hablamos de la corresponsabilidad ${ }^{25}$, término que hace referencia a la responsabilidad compartida de una situación o actuación determinada entre dos o más personas, que en la literatura designa esta necesidad de que las actividades reproductivas dejen de estar privatizadas, en tanto implican importantes cargas de trabajo no remunerado y, puesto que su realización es importante y necesaria para el total de la sociedad, lo justo es que una variedad de actores asuman su responsabilidad sobre este tipo de tareas.

Por tanto, para evitarlo, como señala Soledad Murillo "[La corresponsabilidad] se configura como el único principio que garantiza la igualdad, no como realidad formal, sino como forma sustantiva de convivencia entre hombres y mujeres con los mismos derechos y oportunidades, con los mismos espacios y horizontes profesionales o afectivos, sin tener que vivenciar la daga de una permanente elección" ${ }^{26}$.

En consecuencia, muchas mujeres deben adecuar sus ritmos de trabajo a las necesidades del hogar. Esto significa que el costo de la ausencia de políticas públicas de conciliación es soportado principalmente por las mujeres a través de la intensidad en el uso de su tiempo. Lo cual, como mecanismo de conciliación, deriva no sólo en un impacto negativo sobre su calidad de vida, sino también sobre la calidad de vida de las personas cuyo cuidado depende de ellas. De esta manera, el trabajo doméstico es desvalorizado e invisibilizado en la sociedad. Se piensa que no es necesario ser experta para su desarrollo y, en consecuencia, tiene una baja retribución económica.

En este sentido, las mujeres en situación de vulnerabilidad social son las principales encargadas del cuidado de los miembros de sus propias familias y, por lo tanto, puede suceder que el trabajo doméstico remunerado (con flexibilidad horaria si se realiza por hora y con distintos empleadores) se adapte mejor a sus necesidades de estar presentes en sus hogares. Esta es otra razón importante para que las mujeres con responsabilidades familiares estén sobrerrepresentadas en este tipo de trabajos.

25 El término se ha derivado desde una conceptualización de roles y tareas enmarcado dentro de la sensibilización social que tiene como principal objetivo el lograr la igualdad entre géneros, fomentando de esta forma la conciliación de la vida laboral y familiar. RODRIGUEZ MENÉDEZ, María Carmen, PEÑA CALVO, José Vicente y TORÍO LOPÉZ, Susana. "Corresponsabilidad familiar: negociación e intercambio en la división del trabajo doméstico”. Papers, 95(1), 2010. Págs. 95-117.

${ }^{26}$ MURILLO, Soledad. "Espacio doméstico: el uso del tiempo", en Tobío y Denche (Eds.), El espacio según el género, ¿un uso diferencial?, DGM, Madrid, 1995, pág. 140. 


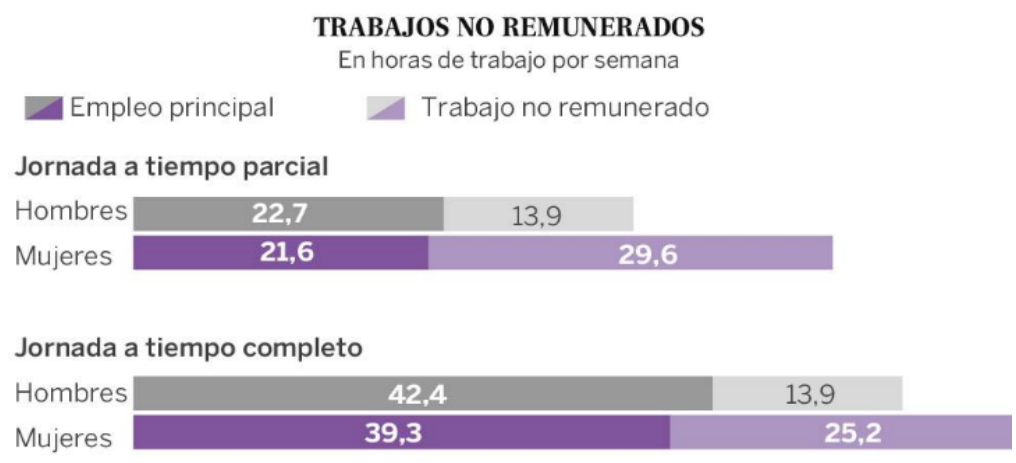

Fuente: Encuesta Nacional de Condiciones de Trabajo ${ }^{27}$

\section{La privatización, invisibilización y feminización del trabajo de cuidados}

Durante la mayor parte del siglo XX el trabajo productivo y reproductivo se organizó sobre la base del modelo tradicional de familia, en el cual el hombre es el jefe de hogar y el encargado de trabajar de manera remunerada y percibir un salario con el cual se asegura la manutención de todos los miembros del conjunto familiar. Por su parte, en dicha configuración la mujer desempeña el rol de ama de casa, y tiene a su cargo las tareas del hogar y de cuidado, a cambio de lo cual no recibe remuneración alguna ${ }^{28}$.

De hecho, Carrasco Bengoa argumenta que la asociación del concepto tradicional de trabajo con empleo remunerado, "no es algo obvio o natural, sino el resultado de un complejo proceso histórico de reconceptualización, que guarda relación con la división sexual del trabajo" y con el modo en que se ha definido el concepto de la economía ${ }^{29}$. Esta asociación fue el resultado de la industrialización que separó definitivamente las esferas públicas y privadas. El trabajo reproductivo, al no ser objeto de intercambio mercantil, quedó marginado de la esfera pública y excluido de los procesos económicos. Además, al conceptualizar el trabajo remunerado con la actividad del mercado se produjo también una asociación con lo masculino ${ }^{30}$.

En consecuencia, el trabajo reproductivo está feminizado a nivel simbólico y a nivel material. La economía feminista muestra que el trabajo reproductivo es naturalizado como algo esencialmente femenino ya que "las mujeres siguen llevando a cabo la mayoría del cuidado no remunerado en los hogares y las comunidades; asimismo, la

27

https://www.insst.es/documents/94886/96082/Encuesta+Nacional+de+Condiciones+de+Trabajo+6\%C2\% AA+EWCS/abd69b73-23ed-4c7f-bf8f-6b46f1998b45 (consultado el 13/10/2020).

${ }^{28}$ CASARES GARCÍA, Esther. "La función de la mujer en la familia. Principales enfoques teóricos. Aposta. Revista de Ciencias Sociales, núm. 36, enero-marzo, 2008, págs. 1-21.

${ }^{29}$ CARRASCO BENGOA, Cristina. "Trabajos, cuidados y sostenibilidad: un desafío para el siglo XXI". El trabajo en el siglo XXI: perspectivas de futuro, 2006, págs. 81-110.

${ }^{30}$ TORNS, Teresa., "El tiempo de las mujeres: entre la invisibilidad y la necesidad" en Cristina Carrasco (ed.) Tiempos, trabajos y género, Publicacions Universitat de Barcelona, 2001, págs. 133-147. 
mayoría de las y los trabajadores del cuidado remunerado son mujeres" ${ }^{31}$. Los hogares, al igual que las demás instituciones, son heteropatriarcales y socializan diferenciadamente a las mujeres y a los hombres.

De ahí que, mientras que las mujeres se crían para ser cuidadoras y madres en las esferas privadas-domésticas, los hombres se crían para ser los "ganadores del pan" y responsables del crecimiento económico en las esferas públicas. La naturalización del trabajo reproductivo como tarea de mujeres produce una división sexual del trabajo, sin la cual el sistema socioeconómico nunca hubiera funcionado ya que necesita todos los trabajos invisibilizados para sostenerse ${ }^{32}$. Debido a lo cual, la mayoría de las familias españolas que deciden externalizar el trabajo de cuidados lo hacen principalmente hacia empleadas domésticas debido a las elevadas ventajas económicas, al mayor tiempo de atención dispensado y a que el tipo de tareas que estas personas ofrecen no se limitan únicamente a los cuidados personales, sino que también engloba actividades relacionadas con el mantenimiento doméstico.

Ahora bien, este modelo hoy necesita ser reestructurado sobre la base de las nuevas realidades y necesidades de las personas y las familias ya que la dinámica familiar se ha diversificado, y la inseguridad e informalidad son en muchas ocasiones, las particularidades del mercado laboral. También se han producido cambios culturales, ya que las mujeres tienen más años de educación formal, valoran la autonomía y participan del mercado productivo, y los/las jóvenes tienen perspectivas diferentes respecto a este tipo de obligaciones.

Ante la escasez de un mercado privado de cuidados profesionales que sea flexible y económico, las familias españolas hayan resuelto el problema externalizando estas tareas hacia el trabajo doméstico, ya que como decimos, este colectivo proporciona tanto cuidados personales como ayuda para el mantenimiento del hogar, de tal manera que, en los últimos años esta opción se ha convertido en la principal vía de privatización ${ }^{33}$.

Esta situación, ha repercutido ampliamente en el mercado laboral del colectivo extranjero, llegando incluso a convertirse en el primer trabajo que encuentran las mujeres inmigrantes recién llegadas. La mayor vulnerabilidad de este colectivo, en muchos casos irregular, provoca que puedan acentuarse las situaciones de abuso y de explotación ${ }^{34}$. Sólo adentrándonos en las características laborales de este sector de asistencia podremos deducir las verdaderas implicaciones de esta actividad sobre las cuidadoras y los receptores del cuidado.

\footnotetext{
${ }^{31}$ PÉREZ OROZCO, Amaia. “Amenaza tormenta: ... op. cit. Pág. 7-37.

${ }^{32}$ GARCÍA SÁINZ, Cristina., SANTOS PEREZ, María Lourdes y VALENCIA OLIVERO, Nelcy. "La construcción social del mercado laboral doméstico en España a comienzos del siglo XXI". Cuadernos de Relaciones Laborales, 32(1), 2014, Págs. 101-131.

${ }^{33}$ MARTÍNEZ BUJÁN, Raquel. "Servicio doméstico y trabajo de cuidados: hacia la privatización del cuidado familiar”. Alternativas. Cuadernos de Trabajo Social. N. 17. 2010). págs. 157-179.

34 SANZ SÁEZ, Concepción. "La discriminación en contra de las empleadas de hogar como forma de manifestación de las discriminaciones múltiples”, Revista de derecho social, № 83, 2018, págs. 89-108.
} 


\section{El cuidado como eje central del bienestar}

Hablar hoy en día de estado de bienestar supone referirnos a un modo de organización social y política con el claro objetivo de intervenir en la economía y lograr el pleno empleo a través de la regulación del mercado, junto con un sector público fuerte con unos servicios sociales de carácter universal a la ciudadanía ${ }^{35}$.

Esta figura familiar basada como decimos, en la división sexual del trabajo, ha favorecido que el desarrollo de los estados de bienestar sea a costa del trabajo realizado por las mujeres en el hogar y no a través de la provisión pública. Las políticas del estado de bienestar han asegurado que las mujeres suministren los servicios de bienestar de forma gratuita, como parte de su responsabilidad en la esfera privada ${ }^{36}$.

En consecuencia, al referimos a las mujeres como principales responsables de las tareas asociadas con lo doméstico y el cuidado, es muy importante analizar las consecuencias que ha tenido la conocida como Ley de la Dependencia ${ }^{37}$, uno de cuyos objetivos era profesionalizar este sector, precisamente para poder descargar a las familias y fortalecer la profesionalización de este. Sin embargo, el sistema económico y social ha invisibilizado este trabajo, ubicándolo como una serie de servicios voluntarios que realizan en su mayoría las mujeres como parte de su identidad de género, por lo que la misma ley es una contradicción, porque la prestación por cuidado familiar sabemos que lo que ha hecho es reforzar las responsabilidades de la familia o en algunos casos ha servido para contratar mano de obra informal, muchas veces insistimos, inmigrante.

Efectivamente, el trabajo doméstico y de cuidados se ha configurado precisamente como una de esas actividades en las que la población extranjera, también principalmente femenina, pueden insertarse al cabo de pocos meses de su llegada a España, de hecho, una de las principales características de la composición de los actuales flujos migratorios que llegan a nuestro país es su tendencia a la feminización ${ }^{38}$.

En este sentido, hay un creciente reconocimiento del cuidado como eje central del bienestar, que implica considerarlo como un bien público y como parte de la responsabilidad social colectiva. Esto constituye un verdadero cambio, ya que, si no puede haber bienestar sin cuidado, y si las políticas de bienestar son centrales para la población, no se puede seguir tomando como "natural" o dar por supuesto el cuidado. Por el contrario, tiene que convertirse en el núcleo básico de las discusiones sobre políticas públicas, como analizaremos más adelante ${ }^{39}$.

\footnotetext{
${ }^{35}$ RUBIO LARA, María Josefa. La formación del Estado Social, MTSS, Madrid. 1991. Pág. 330.

${ }^{36}$ PATTEMAN, Carole. "El estado de bienestar patriarcal", Contextos, año 2, n 5. Pontificia Universidad Católica del Perú, Lima. 2000. Págs. 3-14.

${ }^{37}$ Ley 39/2006, de 14 de diciembre, de Promoción de la Autonomía Personal y Atención a las personas en situación de dependencia.

${ }^{38}$ IZQUIERDO ESCRIBANO, Antonio. "The Favourites of the Twenty-First Century: Latin American Immigration in Spain”, en Studi Emigrazione, n. ${ }^{\circ}$ 149, 2003, págs. 98-124.

39 TORNS, Teresa. "De la imposible conciliación a los permanentes malos arreglos", Cuadernos de Relaciones Laborales, 23, 2005, págs. 15-33.
} 
Tanto es así, que ya en los años sesenta y setenta del siglo XX, cuando la ola feminista actual era incipiente, uno de los desafíos conceptuales fue "hacer visible el invisible" 40 en lo que al trabajo doméstico/mujeres se refiere. Sin embargo, hay todavía un gran iceberg en el plano de las políticas públicas, ya que todavía hay un ingente déficit de reconocimiento de la centralidad del tema del cuidado para el bienestar.

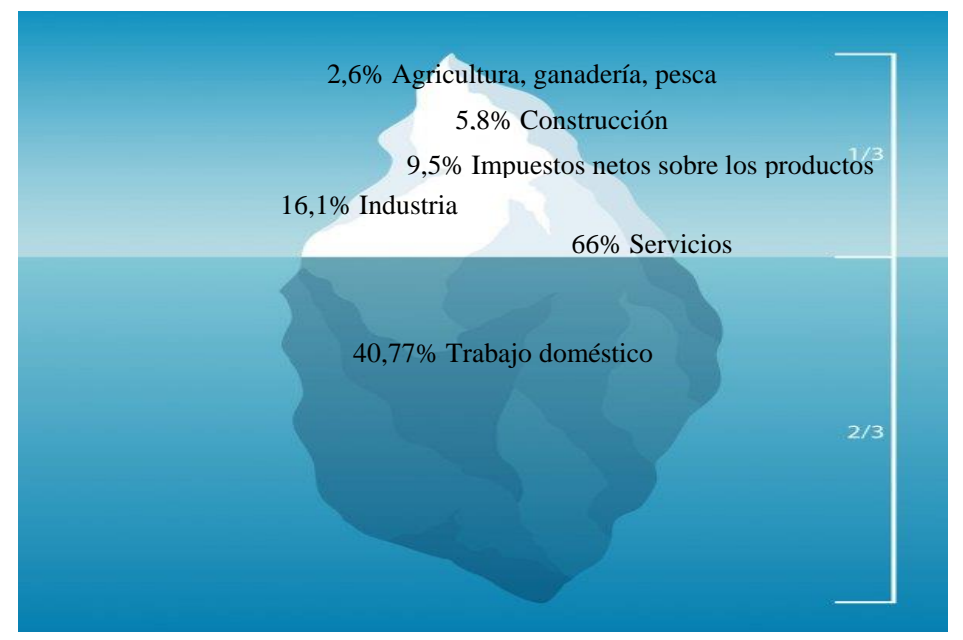

Fuente: ¿Cuánto vale el empleo doméstico en España? Marta Domínguez Folgueras ${ }^{41}$

Sin embargo, la contribución del trabajo de cuidados para el bienestar de la familia, aun siendo cada vez más reconocido, su valor económico es a menudo invisibilizado e infravalorado, ya que de esta manera permite desplazar costes a la esfera doméstica. Como señala la economista Pérez Orozco "en primer lugar, la economía no es reductible a los mercados, sino que economía es mantener la vida, sea o no a través de las esferas monetizadas, y, en segundo lugar, el género funciona como elemento organizador del sistema económico" ${ }^{42}$. Así, el PIB mide el valor de bienes y servicios que se producen en los diversos sectores de actividad, pero deja fuera todo el trabajo que se realiza en los hogares y que es el que sustenta la vida ${ }^{43}$.

También debemos tener en cuenta que el sistema socioeconómico ha excluido aquellos trabajos que sostienen el bienestar humano por el coste de reproducción de la fuerza de trabajo. Le es imprescindible mantener oculto las aportaciones que hace el trabajo doméstico y de cuidados porque consiente a los gobiernos desplazar costes. Como señala Carrasco Bengoa, "parece evidente que la producción mercantil capitalista no podría funcionar pagando salarios de subsistencia real" y desplazando los costes hacia la esfera

\footnotetext{
${ }^{40}$ CRIADO PEREZ, Caroline. La mujer invisible. Aurora Echevarría Pérez (Traductor). Seix Barral Los Tres Mundos. 2020. Págs. 35-46.

${ }^{41}$ DOMÍNGUEZ FOLGUERAS, Marta. ¿Cuánto vale el trabajo doméstico en España? Observatorio Social de La Caixa, 2019.

${ }^{42}$ PÉREZ OROZCO, Amaia. “Amenaza tormenta..., op. cit., pág. 7-37

${ }^{43}$ Fuente: INE. Cuentas nacionales
} 
doméstica les permite pagar "una fuerza de trabajo muy por debajo de sus costes" desplazamiento de estos costes hacia la esfera privada ha conllevado a que estas responsabilidades caigan en mano de las mujeres y que este tipo de trabajo se asocie con lo femenino. Por tanto, desde la mirada de la economía feminista, se puede observar que "el hecho mismo que los mercados capitalistas estén en el epicentro supone que no hay una responsabilidad colectiva en sostener la vida; esta responsabilidad se privatiza, feminiza e invisibiliza" 45 .

La consecuencia de todo lo citado, es que el balance entre trabajo y familia está en un desequilibrio que refuerza las desigualdades socioeconómicas y de género: quienes tienen más recursos, disponen de un mayor acceso a servicios de apoyo y cuidados de calidad y, por ende, a mejores oportunidades de desarrollo. No es posible enfrentar la exclusión social, la desigualdad y la pobreza si no se aborda, al mismo tiempo y con la misma energía, la sobrecarga de trabajo de cuidado de las mujeres.

La conclusión de este análisis es que aún no se han producido rupturas significativas en las concepciones culturales predominantes que consideran que las tareas de cuidado son responsabilidad de las mujeres y no de las sociedades. En consecuencia, existe un espacio importante para el desarrollo de variadas políticas y herramientas a fin de hacer más fluida la interacción entre el ámbito laboral y familiar de las personas. En este sentido, el Estado tiene un rol indiscutible en la generación de políticas de conciliación, el fomento y la articulación de la participación de los demás actores involucrados, como en la provisión de servicios públicos de cuidado y una óptima regulación de los ofrecidos en el mercado.

\section{El empleo doméstico y de cuidados como perfiles convergentes de la profesionalización}

Los trabajos domésticos y de cuidados son actividades que regeneran cotidianamente el bienestar físico y emocional de las personas, establecen las condiciones materiales que hacen posible los cuidados o el trabajo doméstico, así como tareas de coordinación, planificación y supervisión que suponen un gran desgaste mental y emocional para quien las realiza.

Nos encontramos en medio de un cambio fundamental de la conceptualización y de las formas en que se debe proveer estos trabajos, por lo que nos resguardamos en la estructura familiar a través de cuidados informales, de manera que no se atribuye el mérito que les corresponde a los cuidados cuando estos se convierten en un sector profesional, ya que como decimos, a estas tareas nunca se les ha dado valor, ni económico ni social, nos

\footnotetext{
${ }^{44}$ CARRASCO BENGOA, Cristina. "Tiempos y trabajos desde la experiencia femenina”, PAPELES de relaciones ecosociales y cambio global, 108. 2009, págs. 45-54.

45 PÉREZ OROZCO, Amaia. Subversión feminista de la economía. Traficante de sueños, Madrid, 2014, pág. 139.
} 
encontramos que estas mujeres, que entran a formar parte de esos sectores, lo hacen desde la herencia de la precariedad y la invisibilidad.

Pero la dificultad que se plantea al considerar el cuidado como un trabajo, es tanto su remuneración y otras condiciones laborales, como de las cualidades y las competencias que requiere ${ }^{46}$. Son profesiones, como hemos reiterado ya, que están frecuentemente feminizadas, poco valoradas, con escasa remuneración y, en conjunto, con una muy básica cualificación reconocida. Pues esta última no es solo cuestión de especialización, sino que supone la capacidad de efectuar ciertos trabajos y ciertas tareas gracias a un aprendizaje completo y apropiado ${ }^{47}$, con lo que sería posible integrar la parte invisible de las competencias socialmente inculcadas ${ }^{48}$.

En atención a que su ejercicio se pone en acción a través de los conocimientos adquiridos en el mismo proceso de fundamento de la identidad femenina, los trabajos de cuidado están afectados por el abandono que han sufrido históricamente ${ }^{49}$. No obstante, el del cuidado es un sector de gran desarrollo en torno al que se están definiendo nuevas profesiones, y en este razonamiento se ponen en juego muchos otros elementos como la forma de entender el cuidado, la dependencia entre persona cuidadora y cuidada o los límites y deberes que este trabajo implica ${ }^{50}$.

Las tareas del hogar y de atención a la persona formarían el conjunto de actividades del trabajo doméstico, donde las primeras contribuirían a los objetivos de la segunda de forma mediata. La clave por tanto estaría, como ya anticipamos en epígrafes anteriores, en analizar no tanto la tarea en sí misma, sino el entramado de relaciones sociales que permiten el desempeño de esta.

Por todo ello, la economía feminista argumenta que los hogares son lugares de producción al igual que los mercados y que el trabajo de cuidados es, en términos reales, trabajo. Por un lado, los hogares contribuyen a "un ingreso en especie que produce bienestar",51 y por

\footnotetext{
${ }^{46}$ MARTÍN PALOMO, María Teresa. "Domesticación del trabajo: una propuesta para abordar los cuidados". En Rodríguez, Pilar (Ed.), Mujeres, trabajos y empleos en tiempos de globalización. Barcelona: Icaria, 2008. Págs. 53-86.

${ }^{47}$ LALLEMENT, Michel. "Pierre Navielle et la division du travail entre les sexes: le système productif en dernière instance". En Rychter, D., Descoutures, V., Devreux, A-.M. y Varikas, Eleni (dir.), Sous les sciences sociales, le genre. Relectures critiques, de Max Weber à Bruno Latour. Paris: La Découverte, 2010. Págs. 330-332.

${ }^{48}$ KERGOAT, Danièle. "La division du travail entre les sexes". En Kergoat el al, Le monde du travail. Paris: La Découverte, 1998. Págs. 319-329.

${ }^{49}$ MARTÍN PALOMO, María Teresa. "«Domesticar» el trabajo: una reflexión a partir de los cuidados". Cuadernos de Relaciones Laborales, 26 (2). 2008. Págs. 13-44.

${ }^{50}$ SANZ SÁEZ, Concepción. "Profesionalización efectiva del servicio doméstico. Un trabajo pendiente". Lex social: revista de los derechos sociales, Vol. 9, No. 2, 2019, págs. 299-327.

${ }^{51}$ ESQUIVEL, Valeria. El cuidado en los hogares y las comunidades. Documento conceptual. OXFAM Research Reports, $\quad$ Octubre $2013 . \quad$ Pág. 66. http://oxfamilibrary.openrepository.com/oxfam/bitstream/10546/302287/2/rrcare-background-071013es.pdf (consultada el 17/11/2020).
} 
otro, el trabajo de cuidados abarca una serie de costos (tiempo, esfuerzo, recursos) a quiénes lo realizan y una serie de beneficios a la sociedad y al sistema socioeconómico ${ }^{52}$.

Especialmente, la profesionalización de este trabajo supondría el reconocimiento y el prestigio de los conocimientos vinculados al cuidado y, por tanto, la necesidad de contar con personal adecuado y formado para satisfacer las necesidades de estos servicios. Sin duda, en este proceso de transformación del trabajo doméstico y de cuidado en una profesión reglamentada, aún no se cuenta con directrices establecidas para su ejercicio, insistimos que una de las causas es el hecho de ser una actividad históricamente realizada por las mujeres dentro de las familias.

Sería importante, un apoyo a la formación, así como la construcción de un proyecto desarrollo laboral o formativo destinado a mejorar su situación de trabajo, partiendo de la recuperación de los conocimientos y las experiencias adquiridos a lo largo de la vida, para ponerlos en relación con las características del mundo laboral y ayudar a definir los nuevos recorridos que decida seguir en su desarrollo profesional.

En este sentido, es importante destacar que esta propuesta empieza a estar concebida como un primer tramo de un trayecto formativo, pero que se podría continuar desarrollando actividades afines y ampliar así su acceso a otros campos ocupacionales, o incluso generar proyectos de trabajo independientes o asociativos, ya que podría considerarse una opción para las trabajadoras domésticas y de cuidados el cooperativismo, esta opción podría tenerse en cuenta para que además de la profesionalización que permitiría calificar su empleabilidad, estas tareas dejen de realizarse como un trabajo individual e invisible porque no debemos olvidar, que la finalidad de abordar estos temas es superar las marcas de género y promover el trabajo decente para estas trabajadoras que, por lo general, se desempeñan bajo condiciones laborales altamente precarias.

En consecuencia, la formación promueve la reflexión sobre el proceso histórico de feminización de la actividad, resultado de la asignación social de roles diferenciados a varones y a mujeres. Asimismo, propone una mirada crítica sobre la naturalización de dicha asignación de roles y su impacto en la falta de formación profesional de la actividad, pues como ya se ha mencionado, tradicionalmente se ha considerado que las mujeres cuentan "por naturaleza" con un saber "ya dado" para el ejercicio de las tareas domésticas y que, por lo tanto, no sería necesaria ninguna formación específica.

Es importante que las personas realicen el esfuerzo constante de seguir aprendiendo, de seguir capacitándose y poder identificar las mejores oportunidades laborales, pero siempre que esta formación profesional llegue desde el reconocimiento de los saberes de

\footnotetext{
${ }^{52}$ CARRASCO BENGOA, Cristina. "Mujeres, Estado y Bienestar", en Vence y Outes. La Unión Europea y la crisis del Estado de Bienestar. Editorial Síntesis, Madrid. 1998. págs. 169-192. ESTEBAN GALARZA, María Luz. "Cuidado y salud: costes en la salud de las mujeres y beneficios sociales", Congreso Internacional Sare 2003, Cuidar cuesta. Costes y beneficios del cuidado, Vitoria-Gasteiz: EmakundeInstituto Vasco de la Mujer. 2004, págs. 63-80.
} 
las personas o los colectivos como estrategias para la inclusión del colectivo. Así, durante la capacitación se debe realiza un ejercicio de revisión de los aprendizajes adquiridos a lo largo de la vida que pueden ser transferidos hacia un espectro más amplio del mercado de trabajo. Podrán visualizar como algunos de los aprendizajes adquiridos (traducidos en competencias laborales) en su tarea de trabajadoras domésticas y de cuidado será posible que se apliquen en otros ámbitos del mercado de trabajo.

\section{El papel de la OIT para la formación del trabajo decente de cuidados}

Los temas vinculados con las políticas de cuidado son transversales a los objetivos estratégicos de la agenda de trabajo decente, y a su vez relevantes para atender la dimensión de género en cada uno de ellos, tal es así que uno de los temas centrales en la agenda de la OIT es promover el trabajo decente en la economía del cuidado.

Para que el trabajo doméstico y de cuidados sea considerado una "actividad profesional" será necesario identificar cuáles son sus funciones, sus especificidades en términos más precisos, pues como actividad profesional a veces no es reconocida ni siquiera por las propias trabajadoras, menos aún lo es por la sociedad en su conjunto. Pero como iniciamos este artículo, estas actividades son trabajo: lavar, cocinar, ordenar, limpiar, manipular productos, realizar las compras, cuidar, etc., porque constituyen tareas imprescindibles para el funcionamiento social y también para la economía de mercado.

Escuetamente mencionar, que la legislación de la OIT con respecto a la mujer trabajadora experimentó cambios a través del tiempo: desde la protección de las mujeres en relación con su función reproductora, hasta la búsqueda de la igualdad de oportunidades y trato con los varones, comprendida en los convenios protectores e igualitarios de la OIT. Cronológicamente, los convenios protectores son los primeros que aparecen y se caracterizan por otorgar garantías a la mujer en su función biológica de madre -convenios 3 (1919), 103 (1952) y 183 (2000)- o por protegerlas de trabajos considerados peligrosos o inadecuados para ellas -convenios 41 (1934), 89 (1948), 13 (1921) y 127 (1967)-. Por su parte, los convenios igualitarios -100 (1951), 111 (1958), 156 (1981) y 171 (1990)no sólo buscan garantizar el derecho a la no discriminación, sino que además avanzan en crear las condiciones para el logro de la igualdad de oportunidades.

Para esta Organización, el estudio representa una oportunidad de mejorar el conocimiento sobre la formación profesional, objeto de su acción normativa a través del Convenio núm. 142 sobre el desarrollo de los recursos humanos en 1975. Este convenio establece que todo Estado debe desarrollar programas de orientación profesional y de formación profesional, estrechamente relacionados con el empleo, en especial a través de los servicios públicos de empleo. En sintonía con los acuerdos de la Conferencia Internacional del Trabajo de 2008, sobre calificaciones para la mejora de la productividad, el crecimiento del empleo y el desarrollo, se busca promover decisiones tripartitas que apoyen las políticas, asociaciones y cooperación técnica en relación con las competencias 
profesionales necesarias para el cambio tecnológico, el aumento de la productividad y el trabajo decente.

En lo que se refiere a la formación, la OIT en 1998 define la formación profesional como "las actividades que tienden a proporcionar la capacidad práctica, el saber y las actitudes necesarias para el trabajo en una ocupación o grupo de ocupaciones en cualquier rama de la actividad económica",53, es decir, tiene como objetivo lograr una mayor equidad social y asegurar un trabajo decente para todas y todos. Es importante que este concepto de trabajo decente sea tenido en cuenta para la elaboración de las políticas públicas de empleo como forma de mitigar la difícil situación de aquellos colectivos que tienen una relación de empleo particularmente desfavorecida ${ }^{54}$.

Otro impacto de la naturalización del trabajo doméstico y su consecuente desprofesionalización, son las condiciones de precariedad en que históricamente se ha realizado la actividad. En concreto, respecto a nuestro tema principal, en 1948, en su 31 sesión, la Conferencia Internacional del Trabajo consideró la conveniencia de ver en su próxima reunión la situación legal y las condiciones de empleo de las trabajadoras domésticas. Y es en su 100 reunión, celebrada en junio de 2011, donde la Conferencia Internacional del Trabajo adoptó el Convenio sobre el trabajo decente para las trabajadoras y los trabajadores domésticos, y la Recomendación 201 con el mismo título, que lo complementa, por primera vez la OIT elaboraba normas internacionales del trabajo dedicadas específicamente a este grupo de trabajadores/as. A través de estas normas internacionales, no ratificadas aún por España, se propuso promover el trabajo decente para este colectivo que, por lo general, desempeñan el mismo bajo condiciones laborales altamente precarias, y que con sus datos se confirma nuestra teoría de que en su mayoría son mujeres y muchas de ellas, migrantes.

Desafortunadamente y tal como afirma la profesora Grau Pineda ${ }^{55}$, da la sensación de tratarse de un Convenio que ha caído en el olvido y que, salvo la insistencia recurrente del todavía incipiente movimiento asociativo, ha sido imbuida por una desidia que imposibilita la necesaria acción política. Eso se podría cambiar si España ratificara el convenio 189 OIT, cosa que obligaría a igualarles las condiciones de trabajo ${ }^{56}$.

Dicha ratificación sería oportuna realizarla cuanto antes, ya que el último informe de la OIT "El trabajo de cuidados y los trabajadores del cuidado para un futuro con trabajo

\footnotetext{
53 OIT (1998) Informe sobre el empleo en el mundo 1998-1999. Empleabilidad y mundialización papel fundamental de la formación. Ginebra.

54 QUINTERO LIMA, María Gema. "El trabajo de servicio doméstico como una realidad jurídica inevitable". Lex social: revista de los derechos sociales, Vol. 9, №. 2, 2019. págs. 2-6.

55 GRAU PINEDA, María Carmen. "De sirvientas a trabajadoras: la necesaria ratificación del Convenio 189 OIT sobre trabajo decente para las trabajadoras y los trabajadores domésticos". Lex social: revista de los derechos sociales, Vol. 9, N. 2, 2019, págs. 47-90.

${ }^{56}$ GRAU PINEDA, María Carmen. El trabajo doméstico y de cuidados: la incidencia del Convenio 189 OIT sobre trabajo decente para las trabajadoras y los trabajadores domésticos Documentación Laboral, $\mathrm{N}^{\mathrm{o}}$ 116, 2019 (Ejemplar dedicado a: IV Encuentro Ibérico de Derecho del Trabajo. Los Convenios de la OIT: su incidencia en los ordenamientos de Portugal y España), págs. 57-70.
} 
decente" 57 , señala que se generarían un millón de empleos en España atendiendo "los déficits actuales en la prestación de servicios de cuidado y su calidad", basándose en que el trabajo de cuidados comprende los dos tipos de actividades: las actividades de cuidado directo, personal y relacional, como dar de comer a un bebé o cuidar de un familiar enfermo, y las actividades de cuidado indirecto, como cocinar y limpiar.

Como parte del mismo informe, la Oficina de la OIT para España presenta un perfil específico sobre España, donde alerta que de no afrontar los déficits actuales en la prestación de servicios de cuidado y su calidad, se creará una grave e insostenible crisis del cuidado a nivel mundial y aumentarán más aún la desigualdad de género en el trabajo.

Según esta agencia tripartita de la ONU, España se situará, de aquí al 2030, en el puesto 22 de la clasificación de países con mayores ratios de dependencia de cuidados de personas mayores del mundo, y el puesto 19 de los países de Europa y Asia Central con un 9,1 por ciento. Se prevé que el número de beneficiarios de cuidados en España disminuya de los 10 millones actuales ( 7 millones de niños y niñas menores de 15 años y 3 millones de personas ancianas) a 8,8 millones (5,6 millones de niños y niñas menores de 15 años y 3,2 millones de personas ancianas). Apostar por la economía doméstica y de los cuidados, es una apuesta por el bien común que supone la creación de trabajo decente y el aumento del bienestar social, ambos esenciales en la sociedad actual.

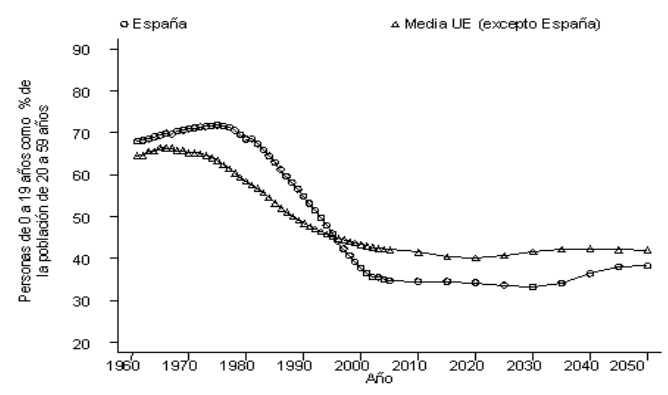

Ratio de dependencia de los jóvenes y de los mayores:

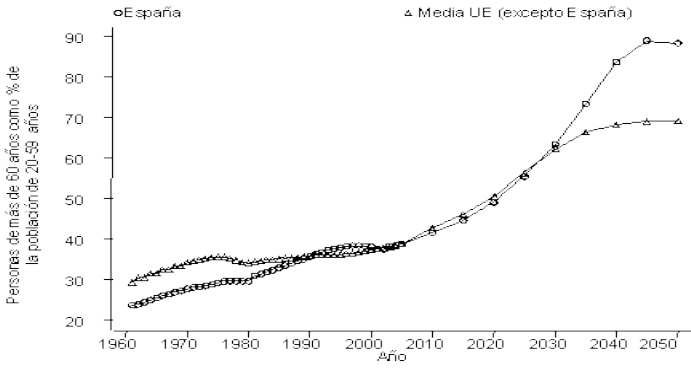
comparación de España con el promedio de la UE.

Fuente: Eurostat, Luxemburgo.

\section{Reflexiones finales}

Dignificar el empleo doméstico y de los cuidados es un asunto que debe ponerse sobre la mesa. Los cuidados y empleo doméstico son trabajos invisibilizados pero imprescindibles para el funcionamiento de la sociedad: las empleadas del hogar y cuidadoras sufren desprotección y precariedad con respecto al resto de personas trabajadoras

\begin{tabular}{llllll}
\hline 57 & Care work and care jobs for the future & of & work \\
https://www.ilo.org/global/publications/books/WCMS & 633168/lang--es/index.htm & (consultada & el
\end{tabular} 19/11/2020). 
A lo largo de este artículo se ha puesto de manifiesto la forma en que el género influye en la asignación de tiempo dedicado al trabajo doméstico y de cuidados. De manera general, se ha observado que las mujeres dedican más tiempo semanal en comparación con los hombres en lo referente a la realización de estas tareas. Dado que hablamos de procesos sociohistóricos fundados en la segregación y especialización sexual, las relaciones de cuidado, al haber sido conducidas históricamente por mujeres, caracterizan el género femenino.

El servicio doméstico de cuidados rompe la dualidad de esta comunicación al formar parte también de la relación la persona que recibe asistencia. Estudiar las formas por las que las relaciones entre la familia empleadora, la persona que recibe los cuidados y la cuidadora transitan entre la dominación, la explotación y el empoderamiento permite acercarse con una mayor proximidad a las transformaciones que hayan podido producirse en las condiciones de trabajo de estas empleadas cuando su actividad principal es la asistencia personal.

Nada se lograría si un sistema, por ser mejor, fuera menos asequible para el usuario y su familia o menos justo para la cuidadora. Las complicaciones legales, burocráticas o económicas dificultan muchas veces el acceso de los usuarios al Servicio de Ayuda a Domicilio y presentan el Sistema Especial de Empleados del Hogar como la alternativa, no mejor, pero viable. Esto también hay que revisarlo y cambiarlo por vía de la simplificación, la flexibilidad y la reducción de costes, ya que, de otro modo, van a aumentar las desigualdades sociales.

Para hacer frente a esta situación es imprescindible reconocer la necesidad urgente e imperiosa de organizar socialmente los cuidados. El sistema que ha funcionado hasta ahora para hacernos cargo de las personas dependientes no va a funcionar en el futuro, la población va a envejecer y está claro que estamos en un contexto de crisis que apunta que no todo puede recaer en el Estado, pero tampoco todo puede recaer en la familia y tampoco puede recaer en los individuos y en el hecho de si tienen o no recursos para poder contratar esos servicios de cuidado.

Asimismo, las mujeres que desempeñan el trabajo doméstico posibilitan la conciliación entre trabajo y familia de otras mujeres, en mejor situación socioeconómica o insertas en trabajos de mayor calidad y remuneración. De esta manera, se configura una "cadena de cuidados" en cuyos diferentes eslabones mujeres reemplazan a otras mujeres en las responsabilidades y tareas domésticas y de los cuidados familiares. Sin embargo, estas mujeres no sólo relevan a las familias y el capital privado de sus responsabilidades hacia la reproducción social, sino que además subsidian al Estado ausente en las políticas sociales al respecto.

Como hemos podido advertir, la promoción de la igualdad de género es un objetivo y un aspecto constitutivo de la Agenda de Trabajo Decente de la OIT. Esto significa que no es posible avanzar en la reducción del déficit de trabajo decente sin al mismo tiempo superar 
las desigualdades de género en materia de derechos laborales, oportunidades laborales y calidad del empleo, protección social y dialogo social.

Para finalizar, ya que estas mujeres tienen una cantidad de competencias, aptitudes y actitudes que no son reconocidas, ni se les paga por ellas, sería necesaria una revisión que dignifique y cualifique estos trabajos a través de revisar la formación de esta relación laboral especial.

\section{Bibliografía}

ANGULO, Carlos y HERNÁNDEZ, Sara. "Propuesta de cuenta de producción de los hogares en España en 2010. Estimación de la serie 2003-2010”, Documentos de Trabajo, 2015. Madrid: INE.

APARICIO RUIZ, María Germana. "Medidas especiales en tiempos de Covid-19: la situación laboral de los empleados de hogar”. Labos, Vol. 1, n. 3.

BARBERÁ HEREDIA, Esther. "Mas allá del techo de cristal". Revista del Ministerio de Trabajo y Asuntos Sociales, No 40. 2002.

BUDIG, Michelle y MISRA, Joy. Los salarios de la economía del cuidado en comparación internacional. Revista Internacional del Trabajo, Vol. 119, Núm. 4. 2010.

CARRASCO BENGOA, Cristina. "Mujeres, Estado y Bienestar", en Vence y Outes. La Unión Europea y la crisis del Estado de Bienestar. Editorial Síntesis, Madrid. 1998.

CARRASCO BENGOA, Cristina. "La sostenibilidad de la vida humana: ¿Un asunto de mujeres?", Mientras Tanto, núm. 82, 2001.

CARRASCO BENGOA, Cristina. "Tiempos y trabajos desde la experiencia femenina", PAPELES de relaciones ecosociales y cambio global, 108. 2009.

CARRASCO BENGOA, Cristina. "Trabajos, cuidados y sostenibilidad: un desafío para el siglo XXI". El trabajo en el siglo XXI: perspectivas de futuro, 2006.

CARRASCO, Cristina., BORDERÍAS, Cristina y TORNS, Teresa (EDS.), El trabajo de cuidados. Historia, teoría y políticas. Catarata, Madrid, 2011.

CASARES GARCÍA, Esther. "La función de la mujer en la familia. Principales enfoques teóricos. Aposta. Revista de Ciencias Sociales, núm. 36, enero-marzo, 2008.

CHACARTEGUI JÁVEGA, Consuelo. "Mujer, discriminación múltiple y exclusión social". En: PÉREZ de la FUENTE ÓSCAR. Mujeres: luchando por la igualdad, reivindicando la diferencia. Madrid: Dykinson, 2010. 
CRIADO PEREZ, Caroline. La mujer invisible. Aurora Echevarría Pérez (Traductor). Seix Barral Los Tres Mundos. 2020.

DOMÍNGUEZ FOLGUERAS, Marta. ¿Cuánto vale el trabajo doméstico en España? Observatorio Social de La Caixa, 2019.

DOMINIJANNI, Ida. "Después del patriarcado. Feminismo y cuestión masculina". Ida Dominijanni, Fina Birulés, Àngela Lorena Fuster, Àngels Vivas (trads.). Lectora 23. 2016.

ESQUIVEL, Valeria. El cuidado en los hogares y las comunidades. Documento conceptual. OXFAM Research Reports, octubre 2013.

ESTEBAN GALARZA, María Luz. "Cuidado y salud: costes en la salud de las mujeres y beneficios sociales", Congreso Internacional Sare 2003, Cuidar cuesta. Costes y beneficios del cuidado, Vitoria-Gasteiz: Emakunde-Instituto Vasco de la Mujer. 2004.

FUHEM TORNS, Teresa. Políticas de tiempos políticas para el bienestar. ¿Tiempos para la igualdad? Reflexiones sobre el tiempo, el género y la organización social. EmkundeInstituto Vasco de la Mujer. 2010.

GARCÍA SAINZ, Cristina. "Entre la ciencia y vida cotidiana". El cuidado de las personas como objeto de conocimiento. En Sociología y realidad social Libro homenaje a Miguel Beltrán Villalva, G. Meil Landwerlin y C. Torres Albero, 2008. CIS.

GARCÍA SÁINZ, Cristina., SANTOS PEREZ, María Lourdes y VALENCIA OLIVERO, Nelcy. "La construcción social del mercado laboral doméstico en España a comienzos del siglo XXI”. Cuadernos de Relaciones Laborales, 32(1), 2014.

GRAU PINEDA, María Carmen. "De sirvientas a trabajadoras: la necesaria ratificación del Convenio 189 OIT sobre trabajo decente para las trabajadoras y los trabajadores domésticos". Lex social: revista de los derechos sociales, Vol. 9, №. 2, 2019.

GRAU PINEDA, María Carmen. El trabajo doméstico y de cuidados: la incidencia del Convenio 189 OIT sobre trabajo decente para las trabajadoras y los trabajadores domésticos Documentación Laboral, N 116, 2019 (Ejemplar dedicado a: IV Encuentro Ibérico de Derecho del Trabajo. Los Convenios de la OIT: su incidencia en los ordenamientos de Portugal y España), págs. 57-70

HARTMANN, Heidi. "Capitalismo, patriarcado y segregación de los empleos por sexos" en Cristina Borderías, Cristina Carrasco, Carmen Alemany (comps.), Las mujeres y el trabajo. Rupturas conceptuales, Fuhem/Icaria, Madrid/Barcelona, 1994.

IZQUIERDO ESCRIBANO, Antonio. "The Favourites of the Twenty-First Century: Latin American Immigration in Spain”, en Studi Emigrazione, n. ${ }^{\circ}$ 149, 2003. 
KERGOAT, Danièle. "La division du travail entre les sexes". En Kergoat el al, Le monde du travail. Paris: La Découverte, 1998.

LALLEMENT, Michel. "Pierre Navielle et la division du travail entre les sexes: le système productif en dernière instance". En Rychter, D., Descoutures, V., Devreux, A.M. y Varikas, Eleni (dir.), Sous les sciences sociales, le genre. Relectures critiques, de Max Weber à Bruno Latour. Paris: La Découverte, 2010.

MARTÍN PALOMO, María Teresa. "Domesticación del trabajo: una propuesta para abordar los cuidados”. En Rodríguez, Pilar (Ed.), Mujeres, trabajos y empleos en tiempos de globalización. Barcelona: Icaria, 2008.

MARTÍN PALOMO, María Teresa. “«Domesticar» el trabajo: una reflexión a partir de los cuidados". Cuadernos de Relaciones Laborales, 26 (2). 2008.

MARTÍNEZ BUJÁN, Raquel. "Servicio doméstico y trabajo de cuidados: hacia la privatización del cuidado familiar". Alternativas. Cuadernos de Trabajo Social. N. 17. 2010).

MURILLO, Soledad. "Espacio doméstico: el uso del tiempo", en Tobío y Denche (Eds.), El espacio según el género, ¿un uso diferencial?, DGM, Madrid, 1995

PARELLA RUBIO, Sonia. "Mujer, inmigrante y trabajadora: la triple discriminación", Ciencias Sociales, n. ${ }^{\circ}$ 36. Barcelona, Anthropos, 2003.

PATTEMAN, Carole. "El estado de bienestar patriarcal", Contextos, año 2, $\mathrm{n}^{\circ} 5$. Pontificia Universidad Católica del Perú, Lima. 2000.

PÉREZ OROZCO, Amaia. "Amenaza tormenta: la crisis de los cuidados y la reorganización del sistema económico”. Revista de Economía Crítica, 5, 2006.

PÉREZ OROZCO, Amaia. Subversión feminista de la economía. Traficante de sueños, Madrid, 2014.

QUINTERO LIMA, María Gema. "El trabajo de servicio doméstico como una realidad jurídica inevitable”. Lex social: revista de los derechos sociales, Vol. 9, №. 2, 2019.

RODRIGUEZ MENÉDEZ, María Carmen, PEÑA CALVO, José Vicente y TORÍO LOPÉZ, Susana. "Corresponsabilidad familiar: negociación e intercambio en la división del trabajo doméstico”. Papers, 95(1), 2010.

RUBIO LARA, María Josefa. La formación del Estado Social, MTSS, Madrid. 1991.

SÁEZ, Gemma, VALOR-SEGURA, Inmaculada y EXPÓSITO, Francisca. ¿Empoderamiento o subyugación de la mujer? Experiencias de cosificación sexual interpersonal. Psychosocial Intervention, 21, 2012. 
SANZ SÁEZ, Concepción. "La discriminación en contra de las empleadas de hogar como forma de manifestación de las discriminaciones múltiples", Revista de derecho social, $\mathrm{N}^{\mathrm{o}}$ 83, 2018.

SANZ SÁEZ, Concepción. "Profesionalización efectiva del servicio doméstico. Un trabajo pendiente". Lex social: revista de los derechos sociales, Vol. 9, N. 2, 2019.

SANZ SÁEZ, Concepción. "Sobre el subsidio extraordinario para las empleadas de hogar en la crisis del COVID-19". Trabajo y derecho: nueva revista de actualidad y relaciones laborales, №. 67-68, 2020.

SARASA URDIALA, Sebastián. "La última red de servicios personales". En: J. Adelantado (Coord.). Cambios en el estado del bienestar: políticas sociales y desigualdades de España. Barcelona: Icaria-UAB. 2000.

TORNS, Teresa. "El tiempo de las mujeres: entre la invisibilidad y la necesidad" en Cristina Carrasco (ed.) Tiempos, trabajos y género, Publicacions Universitat de Barcelona, 2001.

TORNS, Teresa. "De la imposible conciliación a los permanentes malos arreglos", Cuadernos de Relaciones Laborales, 23, 2005

TORNS, Teresa. "El trabajo de cuidados: un camino para repensar el bienestar". En Papeles de relaciones ecosociales y cambio global, T. Torns (ed.), 2012. 